\title{
Parametric Optimization of Electrohydraulic Servo System
}

\author{
Krasimir Ormandzhiev ${ }^{1}$, Stanimir Yordanov ${ }^{2}$, Georgi Mihalev ${ }^{2}$ and Krasen Kostov ${ }^{1}$ \\ ${ }^{1}$ Technical University of Gabrovo, Department of Power Engineering, 4 H. Dimitar str., 5300 \\ Gabrovo, Bulgaria \\ ${ }^{2}$ Technical University of Gabrovo, Department of Automation, Information and Control Systems, 4 \\ H. Dimitar str., 5300 Gabrovo, Bulgaria
}

\begin{abstract}
The electrohydraulic servo systems used in the industrial production are characterized by relatively simple construction, easy operation and high speed, good reliability, functional flexibility and low cost. All this demonstrates the need to study the performance of electrohydraulic servo system primarily in dynamic operating modes. The article studies a mathematical model of electrohydraulic servo system with the typical nonlinearities. The parametric optimization of the automatic PID controller was performed on the basis of minimizing the integral quality criterion when comparing reference and experimental transient processes. The obtained results are shown in a graphical form.
\end{abstract}

\section{Introduction}

Experience in process automation in various industries shows that electro-hydraulic control systems provide the minimum dimensions and mass of the actuators with maximum output power and speed, combined with the convenience of computer control. This explains the increasing use of electro-hydraulic control systems in robotic aggregate, flexible automated production system (FAPS), automatic machines, construction and road machinery, shipbuilding, aircraft and other technical industries. Combining the well-known advantages of electrical communications and control with the speed and relative easiness of powerful hydro-pneumatic drives, these systems displace purely mechanical and electrical systems in control and monitoring.

A distinctive feature of the devices for hydraulic and pneumatic automation consists mainly in the fact that the main circulator of information in them is a liquid or gas. Because the transfer of information is impossible without energy consumption, these agents always work as major energy carriers in a greater or lesser degree. In both cases, it is called "basic" and not "unique", because for the major part the automatic systems in question are essentially hydro-pneumo-mechanical, i.e. information and energy in them pass through a series of transformations from mechanical to hydraulic or pneumatic and vice versa. The object of research in this article is the electrohydraulic tracking systems with regulating throttle (Fig. 1) with control realized in Matlab environment.

Electro-hydraulic servo systems with throttling regulation are widely used in the industry. The fulfilling devices in these systems are usually hydraulic motors with reciprocating 
rectilinear motion, but frequently there are such ones with reflex-rotating or rotating motion. The transient flow in the pressure pipelines $[1,4]$ deteriorates the work of electro-hydraulic servo systems and the operation mode of their governors is complicated. Studies on the electro-hydraulic servo systems with concentrated parameters of the penstocks are made in the work of [3] but the system with distributed parameters are examined in $[1,2,5]$.

Exists many methods for controlling electro-hydraulic tracking systems, such as some modern ones are bidirectional synchronization control [6], adaptive control [7], adaptive neural-bias-sliding mode control [8], Fuzzy control [9], Fault tolerant control [10], Backstepping position control [11], Impedance Model-based Control [12], Neural adaptive control [13], model predictive force control [14] and others. In the study of the control for newly built systems, controllers which already established in theory and practice, based on conventional control laws are usually used. The most commonly used is the PID control law and its variations $[15,16]$.

The article presents a study of the approach for parametric tuning of an automatic regulator for electrohydraulic servo system, using integrated quality criteria.

\section{Mathematical model}

The scheme of electro-hydraulic servo system for realizing the rotating motion of actuating mechanism from Figure 1 is shown in Figure 2.

Electrohydraulic, electropneumatic and electromechanical analogies are usually based only on the external similarity of certain equations (commonly differential equations), which describe electrical, hydraulic (pneumatic) and mechanical appearance and processes.

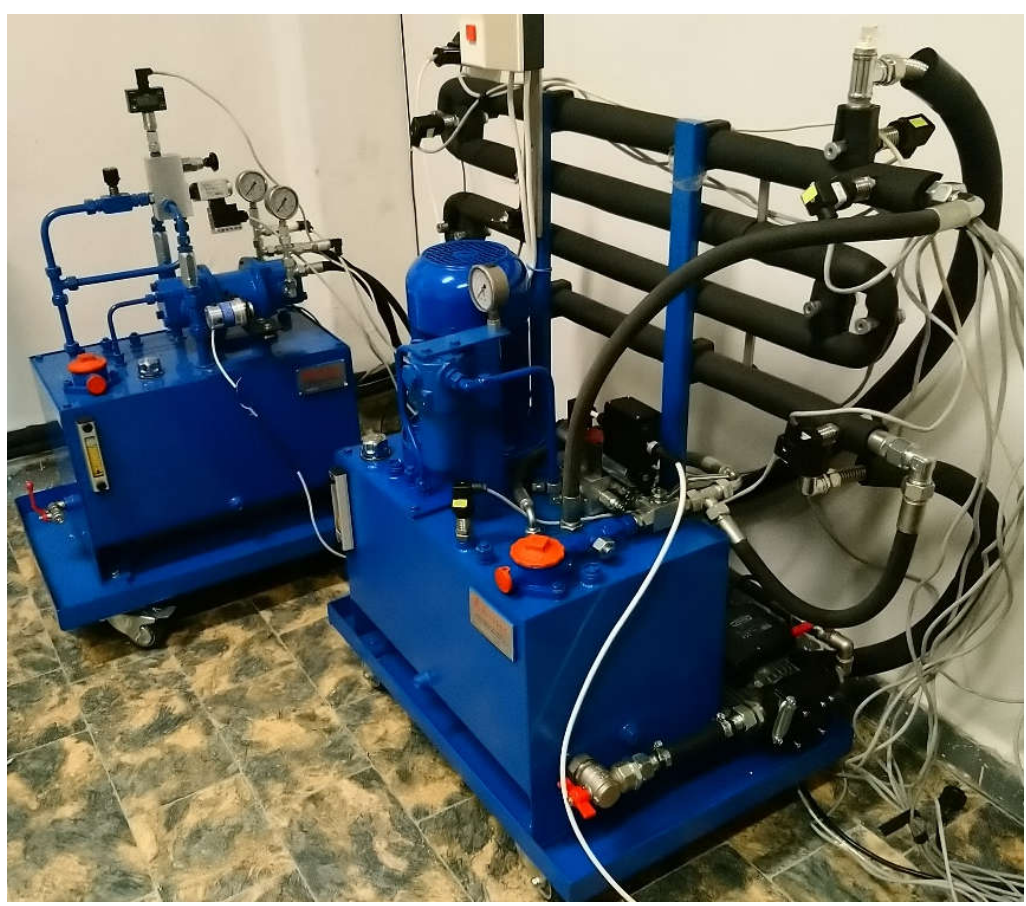

Fig. 1 Test rig of electrohydraulic monitoring system with rotary actuator 
The use of such analogies is convenient and on the basis of them the presented mathematical model of the system is created. The disadvantage of this type of analogy is the difference in the choice of analogues, because, for example, the electric power is formally similar in mechanical and hydraulic systems to both force and pressure, and even temperature, and electric current is similar to volumetric and mass flow rate. Of course, these analogues are described by the same equations, but it is incorrect to try, for example, to describe the behavior of a vector quantity (force, velocity) using a scalar quantity (voltage, current), because the latter quantities generally do not bring information about the direction in space. Furthermore, these arbitrary analogues always prove to be limited, as any change in the aspect of consideration usually destroys them therefore, in order to provide reliable analogies, it is necessary first of all to ensure the correspondence between energy (and its derivatives), as well as between space and time for different physical processes.

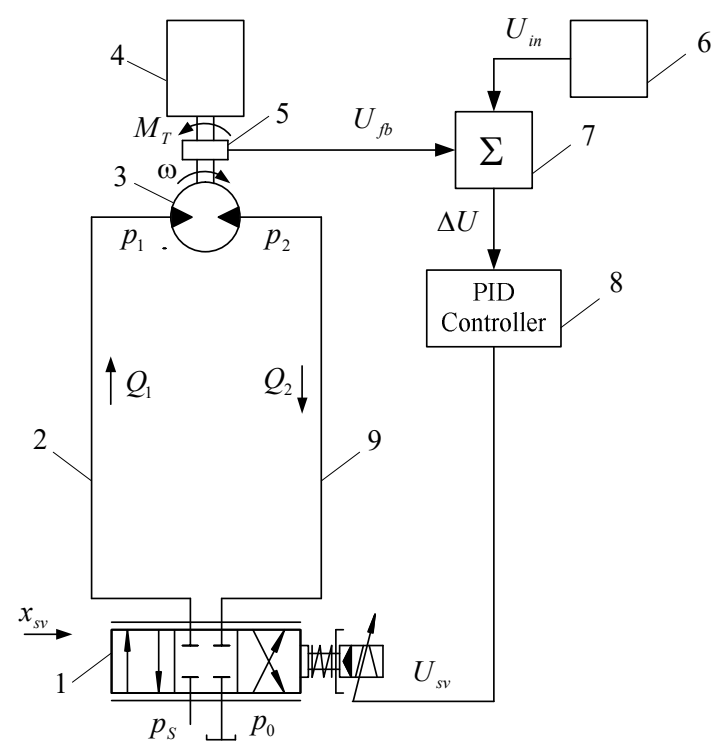

Fig. 2 Scheme of electro-hydraulic servo system for realizing the rotating motion of actuating mechanism

$$
\begin{aligned}
& 1-\text { servo-valve } \\
& 2,9 \text {-pressure pipeline } \\
& 3 \text { - hydraulic motor } \\
& 4 \text { - load }
\end{aligned}
$$

$$
\begin{aligned}
& 5 \text { - tachogenerator } \\
& 6 \text { - setting device } \\
& 7 \text { - sumator } \\
& 8 \text { - PID controller }
\end{aligned}
$$

\subsection{Equation for rotating the shaft of hydraulic motor}

where:

$$
J_{r} \frac{d \omega}{d t}+k_{f} \omega=w_{m}\left(p_{1}-p_{2}\right)-M_{T}
$$

$J_{r} \quad-$ reduced torque of inertia towards the shaft of hydraulic motor, $\left[\mathrm{kg} . \mathrm{m}^{2}\right]$;

$k_{f} \quad-$ coefficient of the hydraulic friction, [N.m.s/rad];

$w_{m} \quad$ - typical (specific) volume of the hydraulic motor, $\left[\mathrm{m}^{3} / \mathrm{rad}\right]$;

$\omega \quad$ - angular speed of the shaft of hydraulic motor[rad $/ \mathrm{s}]$;

$p_{1}, p_{2}$ - pressure on the left (right) chamber of hydraulic motor, $[\mathrm{Pa}]$;

$M_{T} \quad$ - loading torque applied towards the shaft of hydraulic motor, [N.m]. 


\subsection{Equation of the input device}

where:

$$
\Delta U=U_{i n}-U_{f b}
$$

$\Delta U_{f b}=k_{f b} \omega ; U_{\text {in }} \quad-$ setting voltage, [V];

$k_{f b}$ - coefficient of the feedback, [V]; $\Delta U-$ error, [V].

\subsection{Equation of electronic PID-controller}

where:

$$
U_{s v}=k\left(\Delta U+\frac{1}{T_{I}} \int \Delta U d t+T_{D} \frac{d \Delta U}{d t}\right)
$$

$k$ - gain coefficient of the controller;

$T_{I}, T_{D}$ - time-constants of integration and differentiation of the controller, [s].

\subsection{Equation of the servo-valve}

where:

$$
T_{s v} \frac{d x_{s v}}{d t}+x_{s v}=k_{s v} U_{s v}
$$

$T_{s v}$ - time-constant of the servo-valve, [s];

$k_{s v}-$ gain coefficient of the servo-valve, $[\mathrm{m} / \mathrm{V}]$;

$x_{s v}$ - movement of the spool of servo-valve, $x_{\min } \leq x_{s v} \leq x_{\max },[\mathrm{m}]$.

\subsection{Equation for passing flow-rates through the servo-valve}

where:

$$
\begin{aligned}
& Q_{1}= \begin{cases}\mu_{1} \pi d x_{s v} \sqrt{\frac{2\left(p_{S}-p_{1}\right)}{\rho},}, & 0 \leq x_{s v} \leq x_{\max } \\
\mu_{1} \pi d x_{s v} \sqrt{\frac{2\left(p_{1}-p_{0}\right)}{\rho}}, & x_{\min } \leq x_{s v}<0\end{cases} \\
& Q_{2}= \begin{cases}\mu_{2} \pi d x_{s v} \sqrt{\frac{2\left(p_{2}-p_{0}\right)}{\rho}}, & 0 \leq x_{s v} \leq x_{\max } \\
\mu_{2} \pi d x_{s v} \sqrt{\frac{2\left(p_{S}-p_{2}\right)}{\rho}}, & x_{\min } \leq x_{s v}<0\end{cases}
\end{aligned}
$$

$Q_{1}, Q_{2}$ - passing flow-rates through the servo-valve, $\left[\mathrm{m}^{3} / \mathrm{s}\right]$;

$\mu_{1}, \mu_{2}$ - discharge coefficient;

$\rho$ - density of the hydraulic oil, $\left[\mathrm{kg} / \mathrm{m}^{3}\right]$;

$d$ - diameter of the spool of servo-valve, $[\mathrm{m}]$;

$p_{S}, p_{0}$ - supplying and output pressure, $[\mathrm{Pa}]$;

$p_{1}, p_{2}$ - pressure on both sides of the hydraulic motor 2 and 9 (Fig. 1), [Pa]

\subsection{Equation for passing flow-rate through the hydraulic motor}

where:

$$
\begin{aligned}
& Q_{1}=w_{m} \omega+\frac{V_{01}}{B} \frac{d p_{1}}{d t} \operatorname{sign}\left(x_{s v}\right) \\
& Q_{2}=w_{m} \omega-\frac{V_{02}}{B} \frac{d p_{2}}{d t} \operatorname{sign}\left(x_{s v}\right)
\end{aligned}
$$


$V_{01}, V_{02}$ - volume of the left (right) throughput from the proportional valve to the hydraulic motor and half of the volume of the hydraulic motor $V_{01} \approx V_{02}=V_{0}=\frac{1}{2} q_{M}+V_{p v},\left[\mathrm{~m}^{3}\right] ;$

$B$ - bulk modulus, $[\mathrm{Pa}]$;

$V_{p v}=l \frac{\pi d_{\mathrm{Tp}}^{2}}{4}$ - pipeline volume, $\left[\mathrm{m}^{3}\right]$;

$l, d_{m p}$ - distance and diameter of the pipeline between the proportional valve and the hydraulic motor (Fig.2), [m].

\section{System simulation model}

The developed mathematical model describes the operation of the tracking automatic system from fig. 2 in dynamic mode. The simulation model is shown in fig. 3 . For verifying the model, real data is obtained during operation of the stand of Fig. 1 using the Series Data

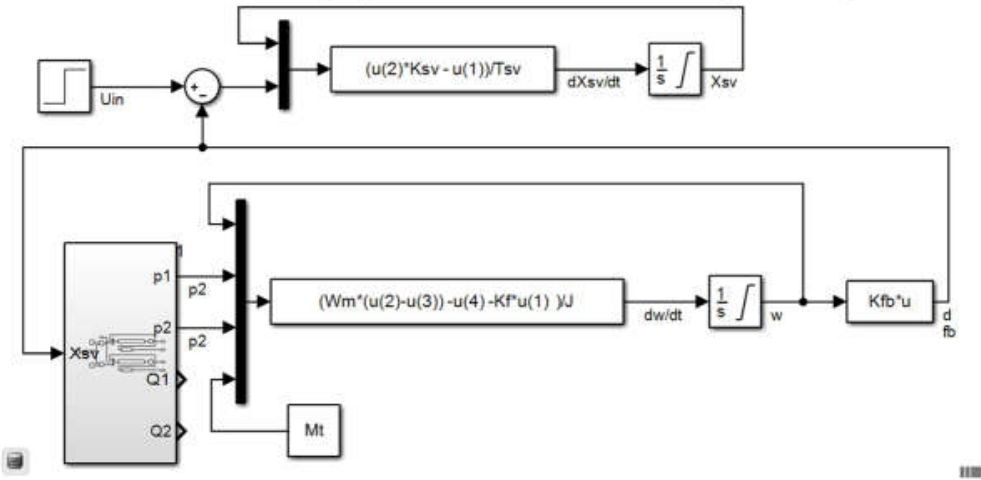

Fig. 3 Simulink system model

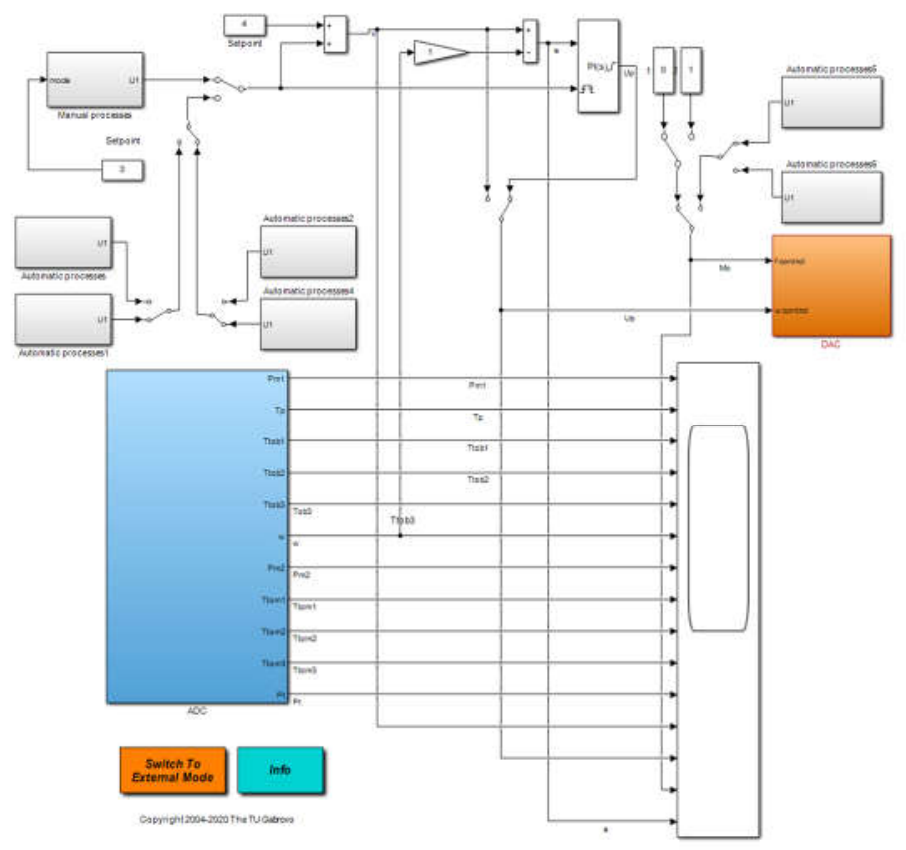

Fig. 4 Simulink model of control system 
Acquisition NI USB-6215 to the analog channels where 11 sensors are connected, three of which are for pressure, 7 for temperature and one is the tachogenerator measuring the speed of the hydraulic motor. The servo valve is controlled by a voltage in the range from $-10 \mathrm{~V}$ to $10 \mathrm{~V}$ put to analog output 0 of the controller. The system load is regulated by a control valve in a dynamic mode, through a voltage in the range $0-5 \mathrm{~V}$, set by the second analog output of the controller. Figure 4 shows a Simulink model of the implemented control, operating in real time. On fig. 5 the step response, when changing the reference of the system without load, is shown.
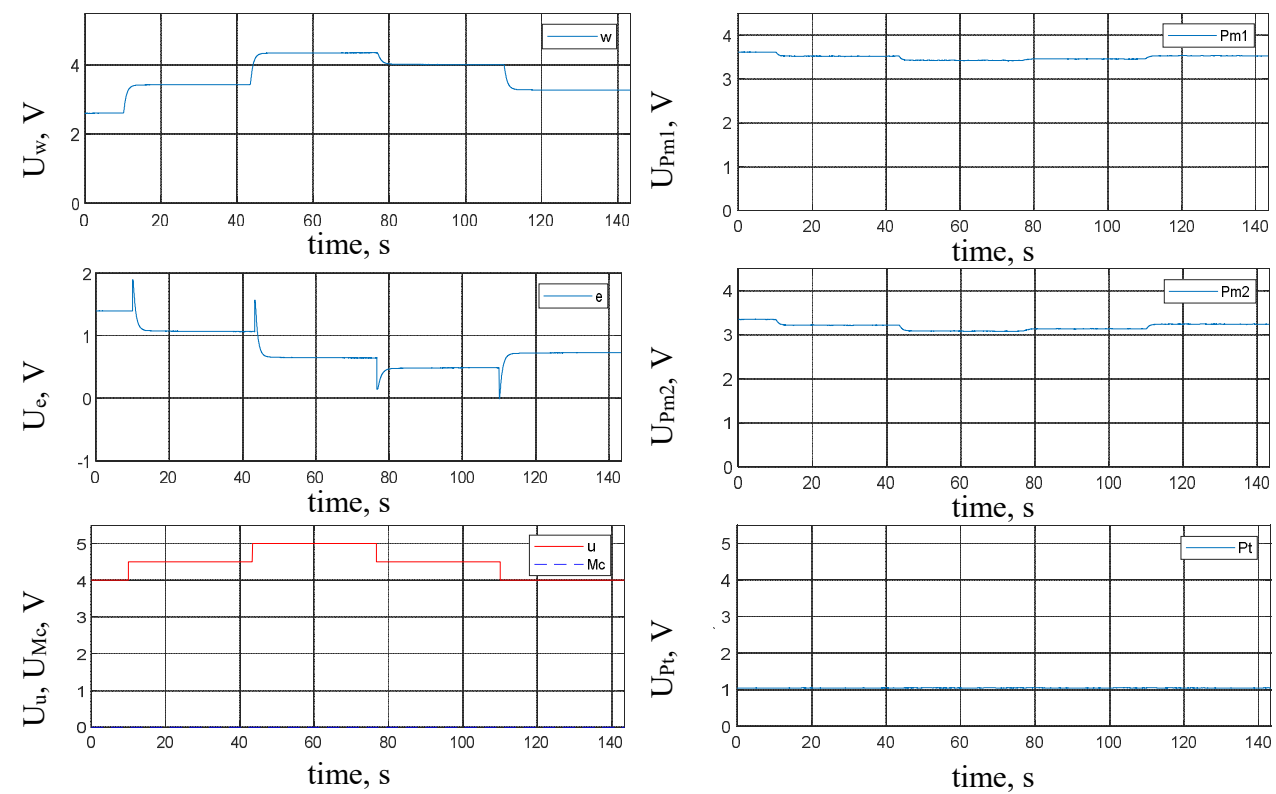

Fig. 5 Step response when changing the reference of the open-loop without load

\section{Parametric optimization of the system}

During operation, automatic control systems are exposed to a serious number of destabilizing factors. The specific operating conditions of the automatic control system (ACS) determine the scale and scope of the changes in these factors. Destabilizing factors can be grouped mainly into five categories: climatic, mechanical, loads, changes in the power supply system, other external factors and disturbances. To minimize their impact, the system needs precise tuning of the controller. Therefore, the task is reduced to parametric optimization of the selected PID controller according to some quality criterion, the formation of which will be based on the requirements of the system as a whole. Firstly, the system error and, as a consequence, the regulation time should be as short as possible, secondly, the overshoot should also be reduced as much as possible in order to increase the life of the system and, finally, to ensure minimum costs for control, as much as possible. Based on the above, we form the quality criterion of the studied system:

where:

$$
J=\int_{0}^{t_{n}} \varepsilon(t)^{2} d t
$$

$$
\varepsilon=\omega_{e}-\omega
$$

$t_{n}$ - time for the step response;

$\omega_{e}$ - angular speed of rotation of the pneumatic motor shaft from the reference process. 
Both processes are started simultaneously: reference and theoretical from the mathematical model of the system. Criterion $\mathrm{J}$ is calculated at each step of the computational process, and its minimum is sought by changing the unknown parameters of the model. The parameters, according to which parametric optimization of the electropneumatic tracking system with rotary actuator is performed, are: $k, T_{I}, T_{D}, k_{f b}$. The eligible values for the controller parameters of the system from Fig.1. have the following values:

- the coefficient of proportionality $\mathrm{k}$, is $[0,001 ; 9]$;

- time for integration TI e $[0 ; 100]$;

- the differential constant of TD is $[0 ; 100]$.

The schematic diagram for performing the system optimization is shown in fig. 6. Fig. 7 shows the Simulink model with which the parametric optimization is performed. The data for model tuning is taken from the actual captured step responses. The values of the parameters before and after the optimization are given in table. 1.

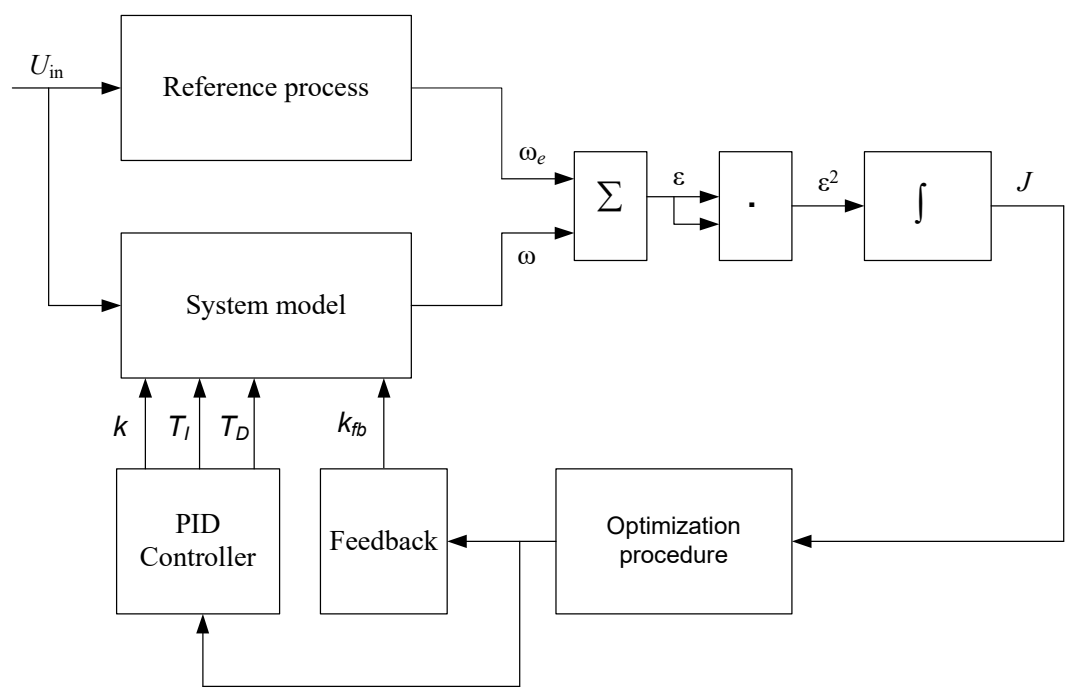

Fig. 6 Scheme for performing parametric optimization.

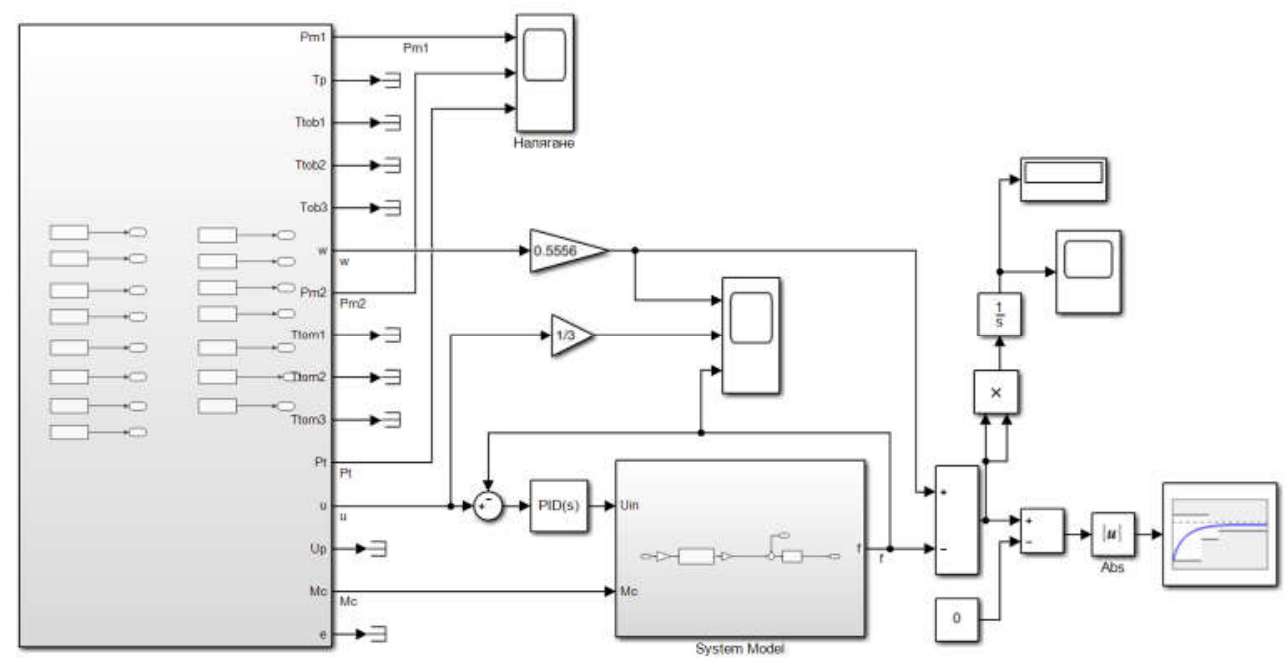

Fig. 7 Simulink model for parametric tuning of the controller parameters 
The experiments were conducted on the developed real electrohydraulic tracking control system shown in fig. 1, developed on the basis of an industrial controller. The communication between the control system, and the visualization of simulation control signals in a MATLAB environment is performed with the Series Data Acquisition NI USB-6215. In the environment of MATLAB, the filtering of the received signals for realization of the law for control, is realized. The system works in real time, and the sampling rate can be changed. The values of the parameters of the PID controller in table 1 are implemented in the controller from fig. 1. Figures 8, 9, 10 and 11 show the step responses obtained as a result of the operation of the system with the two regulators, when changing the reference and the load.

Table 1. Parameter values before and after optimization

\begin{tabular}{|c|c|c|c|c|c|}
\hline Tuning method & $k$ & $T_{I, s}$ & $T_{D}, s$ & $k_{f b, V s \mathrm{rad}^{-1}}$ & $J$ \\
\hline \hline Ziegler-Nichols & 0.800 & 0.850 & 0.100 & 1.000 & 0.0821 \\
\hline Parametric optimization & 0.642 & 0.052 & 0.750 & 0.996 & 0.0143 \\
\hline
\end{tabular}

The analysis of the characteristics shows that the transient process when changing the setpoint for the non-optimized system has an oscillatory character with re-regulation $\sigma=$ $12.5 \%$. The settling time is $t_{p}=15, s$. In the optimized system, the transient process is aperiodic with a settling time $t_{p}=7.5$, $s$. Therefore we can conclude that the optimization of the system, according to the integrally quadratic criterion, provides a better quality of the step response process, compared to the Ziegler-Nichols method. The analysis of the obtained results, shows that the parameters of the controller presented in Table 1 are optimal with respect to the relevant criterion.
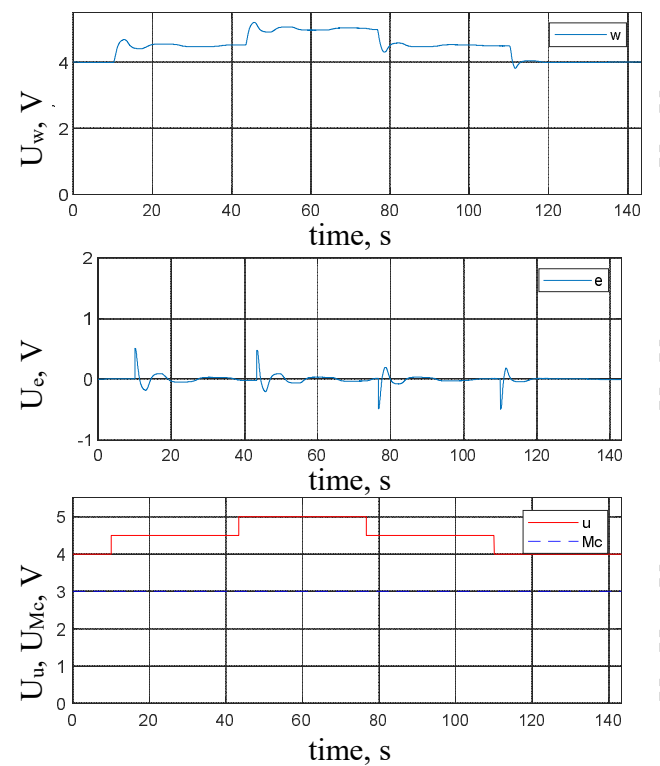

Fig. 8 Step response when changing the reference of the non-optimized system
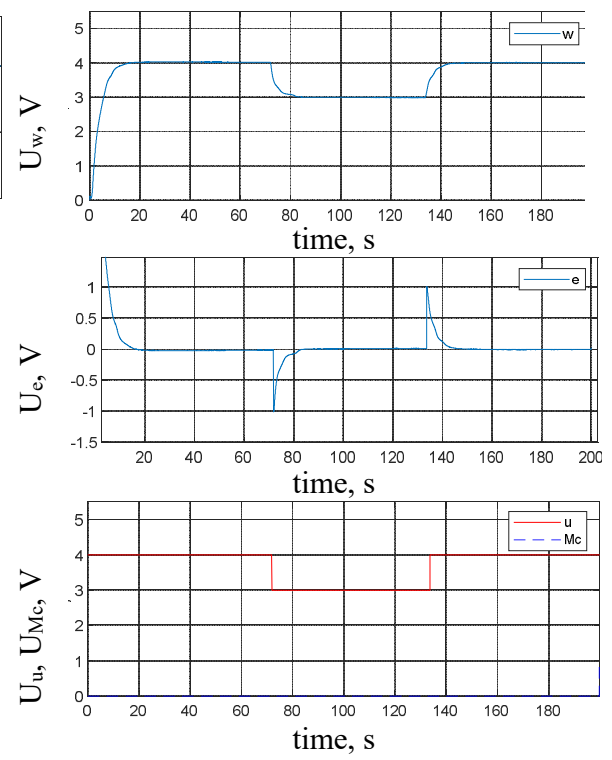

Fig. 9 Step response when changing the reference of the optimized system 

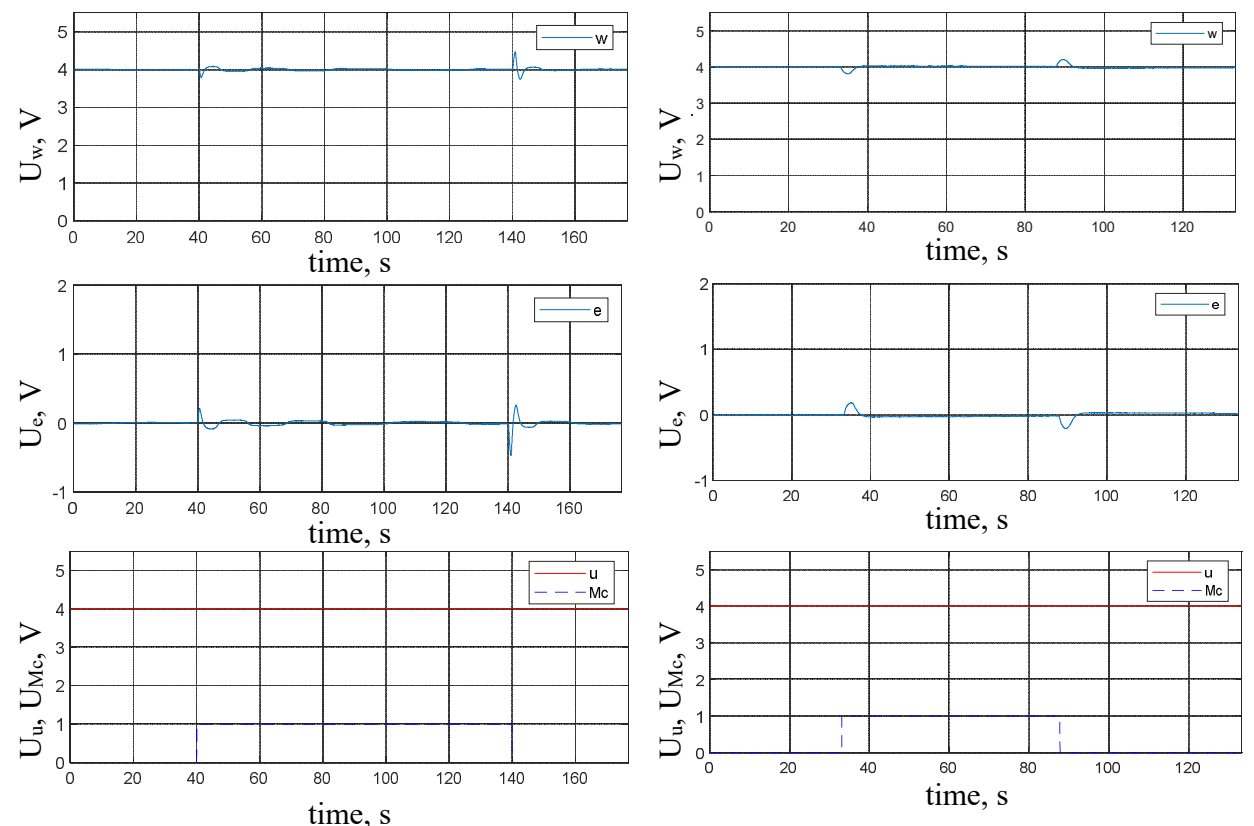

Fig. 10 System response to load change of the non-optimized system

Fig. 11 System response to load change of the optimized system

\section{Conclusions}

A method for determining the parameters of PID control of industrial objects and systems, is proposed. To conduct the experiments, An electrohydraulic tracking system developed by the authors, was used. The developed mathematical model, gives the opportunity to determine the dynamic processes, in the considered monitoring electrohydraulic system with a rotary actuator, under different laws for changing the load of the hydraulic motor and the reference voltage. With the selected PID controller, the optimal settings can be reached relatively easily, as it varies only with three parameters.

Experimental results before and after performing parametric system optimization are shown. The results shown an improvement in the quality of the step response processes, as the criterion for optimality reduces its value 5.74 times. Aperiodic step responses on assignment and interference with significantly shorter duration were obtained (less than 10s).

A more precise consilience between the reference and the optimal process can be achieved if a structural optimization is performed and an optimal control law is synthesized, on the basis of which a corresponding real regulator is developed. The present work can be developed by synthesizing and building a fuzzy regulator of the tracking system.

\section{References}

1. J. Watton, The Dynamic Performance of an Electrohydraulic Servovalve/Motor System with Transmission Line Effect, Journal of Dynamic Systems, Measurement and Control, March 1987, Vol. 109, pp. 14-18 (1987)

2. T. Lieno, M. Linjama, K. Koskinen and M. Vilenius, Applicability of Laminar Flow Based Model in Pipeflow Modeling of Water Hydraulic Systems, International Journal of Fluid Power, August 2001, Vol. 2, Nr. 2, pp. 37 - 45 (2001) 
3. E. Kojima, M. Shinada, J. Yu, Development Accurate and Practical Simulation Technique Based on the Modal Approximations for Fluid Transients in Compound Fluid-Line Systems, International Journal of Fluid Power, August 2002, Vol. 3, Nr. 2, pp. 5 - 13 (2002)

4. K. Ormandzhiev, T. Todorov, Numerical Method for Determination of the Dynamical Process in Pressure System of Hydro Power Station with Parallel Working Hydraulic Turbo-alternators, Research and Development in Mechanical Industry, in Proceedings, Herceg Novi, Serbia and Montenegro, 2003, Vol 3., pp.1866 - 1875 (2003)

5. M. Saad, H. Jamaluddin, I. Darus, Implementations of PID-controller tuning using differential evolution and genetic algorithm, International Journal of Innovate Computing, Information and Control. 2012. Vol. 8, no. 11. pp. $7761-7779$ (2012)

6. Y. Sang, W. Sun, F. Duan, J. Zhao, Bidirectional synchronization control for an electrohydraulic servo loading system, October 2019, Mechatronics, (2019).

7. H. Yanada, K. Furuta, Adaptive control of an electrohydraulic servo system utilizing online estimate of its natural frequency, Mechatronics, 2007, pp. 337-343 (2007)

8. S. Chaudhuri, R. Saha, A. Chatterjee, S. Mookherjee, D. Sanyal, Adaptive neural-biassliding mode control of rugged electrohydraulic system motion by recurrent Hermite neural network, Control Engineering Practice (2020)

9. Kalyoncu, M., M. Haydim, Mathematical modelling and fuzzy logi based position control of an electrohydraulic servosystem with internal leakage, Mechatronics, 2009, pp. 847-858 (2009)

10. A. Schwung, M. Beck, J. Adamy, Fault diagnosis of dynamical systems using recurrent fuzzy systems with application to an electrohydraulic servo axis, Fuzzy Sets and Systems, 2015, pp. 138-153 (2015)

11. I. Ursu, , F. Ursu, F. Popescu, Backstepping design for controlling electrohydraulic servos, Journal of the Franklin Institute, 2006, pp. 94-110 (2006)

12. I. Davliakos, E. Papadopoulos, Impedance model-based control for an electrohydraulic Stewart platform, European Journal of Control, 2009, pp. 560-577 (2009)

13. Q. Guo, Z. Chen, Neural adaptive control of single-rod electrohydraulic system with lumped uncertainty, Mechanical Systems and Signal Processing, Vol. 146, January 2021, 106869 (2021)

14. P. Marusak, S. Kuntanapreeda, Constrained model predictive force control of an electrohydraulic actuator, Control Engineering Practice, Vol. 19, January 2011, pp. 6273 (2011)

15. Y. Chen, Y. Ma, W. Yun, Application of Improved Genetic Algorithm in PID Controller Parameters Optimization, Telkomnika, 2013, Vol. 11, no. 3, pp. 1524-1530 (2013)

16. A. Y. Jaen-Cuellar, R. de J. Romero-Troncoso, L. Morales-Velazquez, R. A. OsornioRios, PID-Controller Tuning Optimization with Genetic Algorithms in Servo Systems, International Journal of Advanced Robotic Systems, 2013, Vol. 10, P. 324. DOI: $10.5772 / 56697$ (2013) 